\title{
Development of mathematical model for lower urinary tract dysfunctions
}

\author{
Mohanad A.Deaf ${ }^{1}$, Mohamed A.A.Eldosoky ${ }^{1}$, Ahmed M. El-Garhy ${ }^{2}$, Hesham W.Gomma ${ }^{2}$, Ahmed S.El-Azab ${ }^{3}$ \\ Dept. of Biomedical Engineering, Faculty of Engineering, Helwan University, Egypt ${ }^{1}$ \\ Dept. of Electronics, Communications and Computers, Faculty of Engineering, Helwan University, Egypt ${ }^{2}$ \\ Sec. of Female Urology and NeuroUrology, Urology Dept., Faculty of Medicine, Assiut University , Assiut, Egypt ${ }^{3}$
}

\begin{abstract}
The main objective of this paper is to simulate different types of diseases that cause deformities which occur in the lower urinary tract system together with abnormal micturition, which results from these diseases. To achieve this a modified version of the normal micturition process model proposed by William Fletcher [1] was developed and simulated using MATLAB. The new model is assuming abnormal nerve signals and bladder, ureteral muscles disorders The newly developed model allows to simulate six types of lower urinary tract system (LUTS) disorders caused by dysfunctions in bladder, urethral muscles and nerves control system and gives mathematical representation for abnormal micturition process.

Moreover, the simulation developed has got a wide number of advantages in the medical sector such as design intelligent control scheme to correct any deformations that occur in lower urinary tract system, and can be allowed to test the system safely before trial with humans.
\end{abstract}

Keywords: lower urinary tract system (LUTS) disorders, Abnormal micturition, Bladder Output Relation(BOR), Urethral Resistance Relation (URR) .

\section{INTRODUCTION}

The Lower Urinary Tract (LUT) consists of the urinary bladder the urethra. And are controlled by the nerve signals . The bladder is a hollow muscular, and distensible (elastic) organ, the bladder sits on the pelvic floor [2]. Urine enters the bladder via the ureters and exits via the urethra. The urethra is a tube that connects the urinary bladder to the outside of the body and surrounded by a sphincter muscles[3].

The LUT has 2 main functions[4]: storage of urine and voiding. Normally, during the filling (storage) phase, the pressure inside the bladder (intravesical pressure Pves) should be kept low despite the urine accumulation in the bladder, due to the vesicoelastic properties of the bladder wall. In addition, bladder filling is characterized by an appropriate bladder sensation and absence of any unstable detrusor contractions (i.e. bladder is silent during filling)[5].

The sphincter mechanism is activated during filling to preserve continence and prevent any leakage of urine. During voiding, the muscle in the bladder wall (detrusor muscle) contracts to expel urine while the sphincteric mechanisms around the urethra relax to allow voiding. During filling the bladder pressure is lower than the pressure inside the urethra and therefore the bladder neck remains closed. As the bladder continues to fill, bladder pressure rises[4].

The loss of normal bladder, urethral and neurogenic controlled functions to cause abnormal micturition, large numbers of people of both sexes, suffer from lower urinary tract disorders[3]. Lower urinary tract disorders are not only socially inconvenient. Occasionally, they can even be lethal [3].
Developing LUTS mathematical model which has been proposed by William Fletcher, we were able to simulate six types of lower urinary tract system (LUTS) disorders which are: absence bladder contraction caused by Nervous signals disorder, Absence bladder contraction caused by bladder muscles disorder, absence Urethra contraction caused by nervous signals disorder , Obstructed urine Flow, Irregular urine Flow and Intermittent urine Flow .

Remaining of this paper is organized as follows: A brief review of the LUTS mathematical model is presented in section II. Section III presents the Simulation of normal micturition. The simulation of abnormal micturition is presented in section IV. This is followed by the conclusions in section $\mathrm{V}$.

\section{MATHEMATICAL MODEL FOR LUTS}

The LUTS mathematical model can be compartmentalized into three main sections [1] the bladder, the urethra and their nervous control. Each of these components of the model shall be outlined in this section.

\section{A. Nervous Control}

The neurogenic control of micturition has been represented by two nerve signals[6], one that controls the contraction of the bladder muscle and another that controls urethral relaxation, hereafter called $S_{1}$ and $S_{2}$ respectively. As shown in Fig.1.The functions which describes this nerve signals are given as [1]:

$$
\begin{aligned}
& \mathrm{S}_{1}=1-e^{-k_{1} t} \\
& \mathrm{~S}_{2}=(1-\mathrm{C}) \mathrm{e}^{-\mathrm{k}_{2} \mathrm{t}}+\mathrm{C}
\end{aligned}
$$


Where $\mathrm{t}$ is time, and $\mathrm{k}_{1}$ and $\mathrm{k}_{2}$ control the nerve signals rate of increase or decrease, $\mathrm{C}$ is the relative level that the urethral relaxation decreases to.

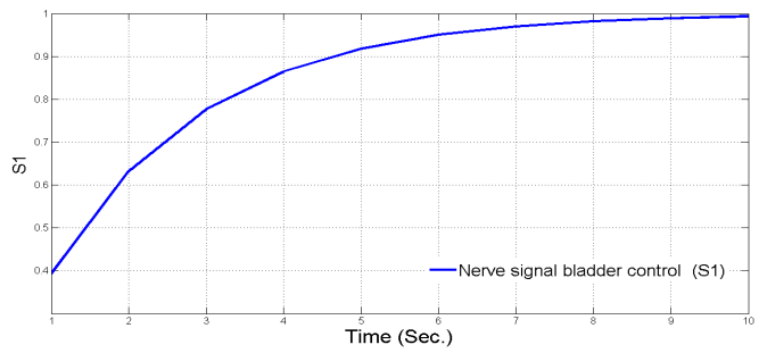

(a)

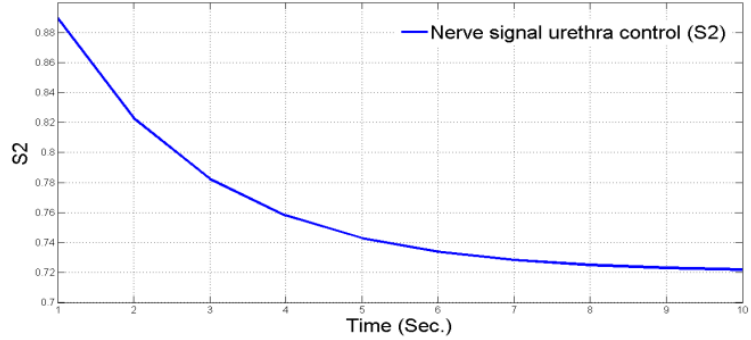

(b)

Fig.1: a) the nerve signals that control bladder excitation b) urethral relaxation (Right)

\section{B. Bladder}

The bladder has been represented mathematically by an equation called Bladder Output Relation (BOR)[1]. The pressure in the bladder and the rate of bladder evacuation are opposite ends. The functions describing the (BOR) are given as:

$$
\begin{aligned}
& \left(P_{d}+\frac{P_{O}}{4}\right)\left(Q+\frac{Q_{O}}{4}\right)=\frac{5}{16} P_{0} Q_{0} \\
& P_{O}(r, t)=P_{m} \frac{F_{O}(r)}{\pi r^{2}} s_{1} \\
& Q_{O}(r, t)=Q_{m} 2 r^{2} v_{\max } s_{1} \\
& F_{O}=-2.04\left(\frac{r}{r_{o}}\right)^{2}+4.08\left(\frac{r}{r_{0}}\right)-1.04
\end{aligned}
$$

$\mathrm{P}_{\mathrm{d}}$ is detrusor pressure, $\mathrm{Q}$ is flow rate, $\mathrm{P}_{0}$ and $\mathrm{Q}_{0}$ are parameters that determine the shape of the curve as they represent the intercepts of the curve with the axes, $\mathrm{F}_{0}$ is the isometric force, $\mathrm{r}$ is bladder radius and $\mathrm{P}_{\mathrm{m}}$ and $\mathrm{Q}_{\mathrm{m}}$ are maximum values.

\section{Urethra}

Urethra and sphincter muscles are represented mathematically by an equation called Urethral Resistance Relation (URR) [1], It is a direct relation between Urethral pressure $(P u)$ and urinary flow rate. The URR is described by:

$$
\begin{aligned}
& P u=P_{O P}+m Q \\
& P_{O P}=P_{h} s_{2} \\
& m=m_{h} s_{2}
\end{aligned}
$$

$\mathrm{P}_{\text {op }}$ represents the urethral opening pressure (the pressure required to distend the elastic wall of the urethra and start flow), $\mathrm{m}$ is the urethral resistance, $P_{h}$ and $m_{h}$ are maximum values. The change in the values of (Pop) and $(\mathrm{m})$ is based on the changing in the values of $\left(\mathrm{S}_{2}\right)$ by time to ensure full relaxation of urethra to allow the emptiness of the bladder.

\section{SIMULATION OF NORMAL MICTURITION}

Simulation of normal micturition is shown in Fig.2. by "snapshots" of Bladder Output Relation (BOR) and Urethral Resistance Relation (URR) curves . Change in bladder and urethral control nerve signals $S_{1}$ and $S_{2}$ is shown in Fig. 3 and Fig. 4 starting from $t_{1}$ to $t_{5}$ that Cause change in $\left(\mathrm{P}_{0}, \mathrm{Q}_{0}\right)$ and $\left(\mathrm{P}_{0 \mathrm{p}}, \mathrm{m}\right)$ as following :

1. The model has 6 parameters $\left(\mathrm{K}_{1}, \mathrm{~K}_{2}, \mathrm{C}, \mathrm{r} 0, \mathrm{P}_{0}, \mathrm{~V}_{\max }\right.$, $\mathrm{P}_{\mathrm{h}}, \mathrm{m}_{\mathrm{h}}$ ) was taken as a reference no. (1)

2. Calculate $\mathrm{P}_{01}$ and $\mathrm{Q}_{01}$ at $\mathrm{t}_{1}$.

3. Calculate $\mathrm{P}_{\mathrm{op} 1}$ and $\mathrm{m}_{1}$ at $\mathrm{t}_{1}$.

4. Using these values to plot the first snapshot for Bladder Output Relation (BOR) and Urethral Resistance Relation (URR).

5. Repeat the whole previous process to find the next snapshot.

6. When the two curves BOR and URR intersect that means that the urine is leaking out through the urethral from the bladder. When the two graphs do not intersect, $\mathrm{Q}=0$.

7. To complete this simulationthe bladder and urethra must be return to initial pressure and flow rate $\left(\mathbf{P}_{\mathbf{0 1}}, \mathbf{Q}_{01}\right)$ and $\left(\mathbf{P}_{\mathbf{0 p 1}}, \mathbf{m}_{\mathbf{1}}\right)$ after send control nerve signal at $\mathrm{t}_{(5-1)}$
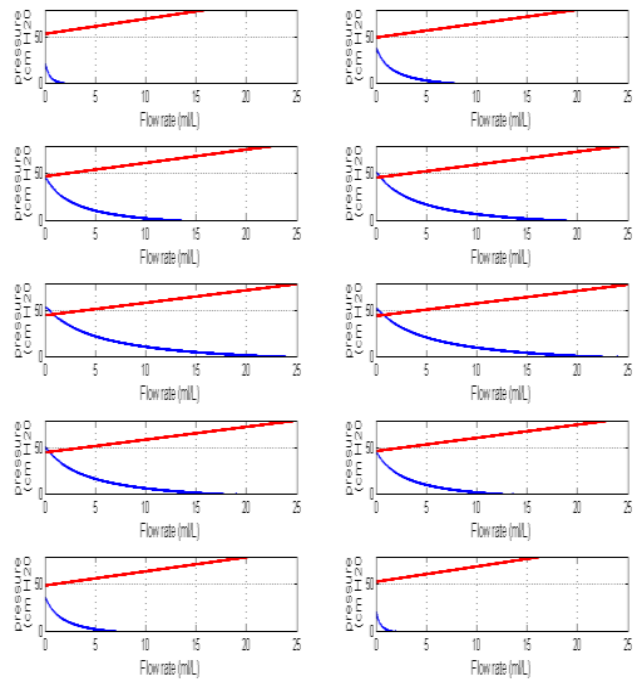

Fig.2: Simulation of normal micturition

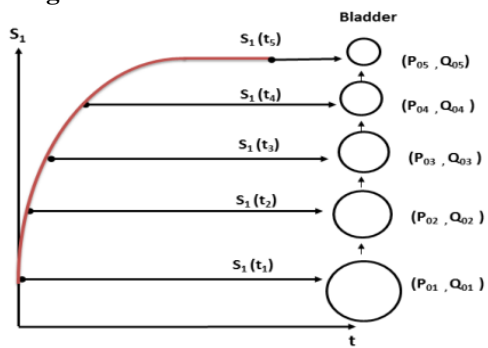

(a)

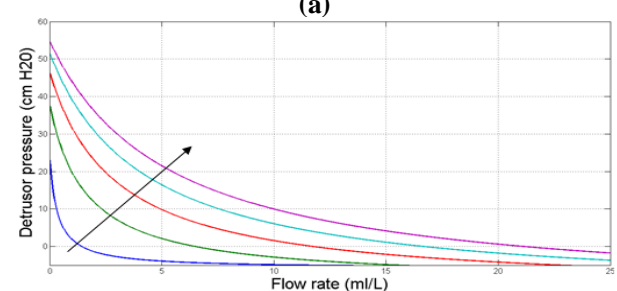

(b)

Fig.3: : a) Bladder contraction in response to nerve signals. b) Bladder Output Relation (BOR) change in response to nerve signals. The arrows shows the direction of increasing stimulation 


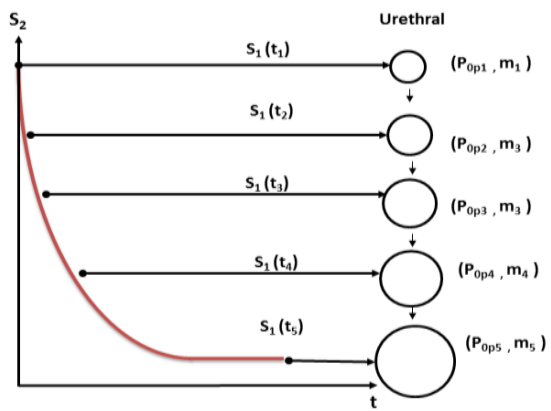

(a)

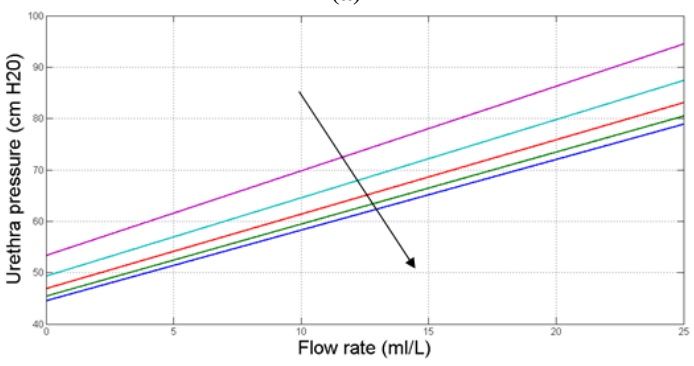

(b)

Fig.4: a) Urethral relaxation in response to nerve signals. b)Urethral Resistance Relation (URR) change in response to nerve signals. The arrows shows the direction of increasing relaxation

\section{SIMULATION OF ABNORMAL MICTURITION}

As shown in the flow chart in fig.5. The changes of the values $(\mathrm{r}),\left(\mathrm{S}_{1}\right),\left(\mathrm{S}_{2}\right)$ and $\left(\mathrm{P}_{\mathrm{h}}\right)$ whereas they must change by time. So, we ensure that the bladder is contraction and relaxation of urethra to allow the emptiness of the bladder [7].

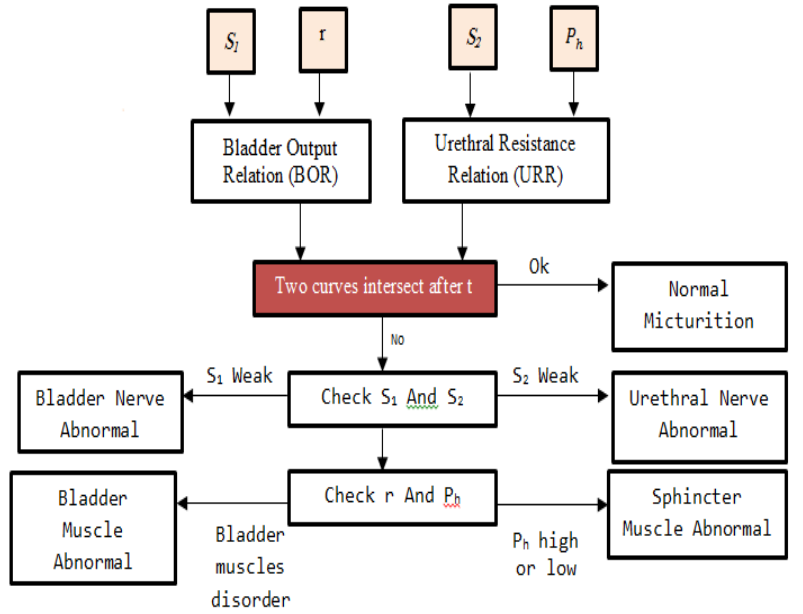

Fig.5:. Flow chart of normal and abnormal micturition When occurrence of any abnormal change of any this values, causes abnormal micturition, this paper represents the following diseases:

\section{A. Absence bladder contraction caused by Nervous} signals disorder

This case means that the nerves signal $\left(\mathrm{S}_{1}\right)$ that controls the contraction of the bladder muscle had been sent weak [8] within time (T) as shown in Fig.6 . The mathematical functions which describing the nerve signal disorder is given as constant function (10), whose (output) value is the same within time $(\mathrm{t})$.

$$
\mathrm{S}_{1}(\mathrm{t})=0.5 \text { for } 10>=\mathrm{t}>=0
$$

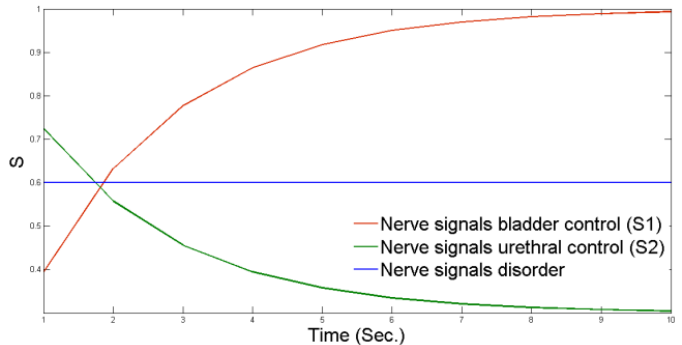

Fig.6: Nerve signals normal and disorder that control bladder excitation and urethral relaxation

Consequently, the value of bladder radius ( $r$ ) does not change. This means that the bladder is unable to contract and keeping urine inside the bladder, this causes absence of intersection between bladder and urethral curves as shown in Fig.7. Although the urethral was noticed to work normally which indicates that the bladder is malfunction.
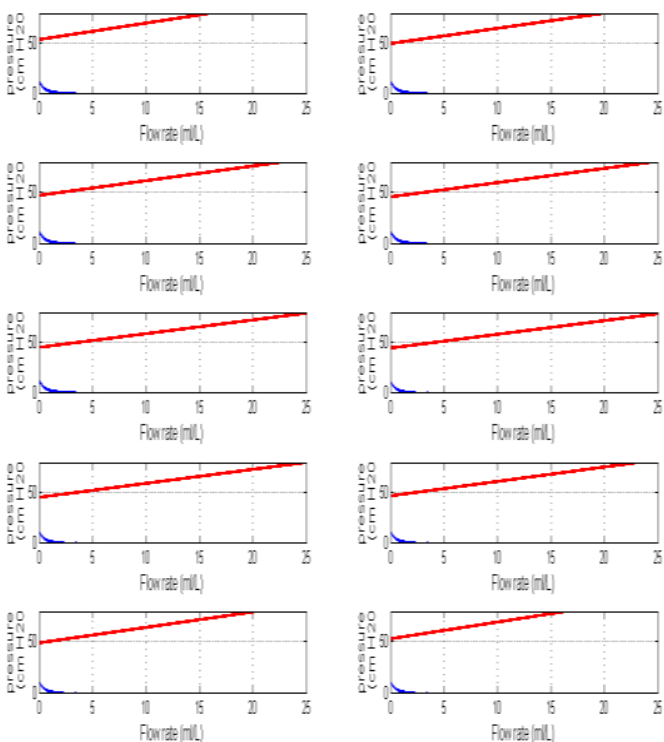

Fig.7: Absence bladder contraction caused by nervous signals disorder

$B$.

Absence bladder contraction caused by bladder muscles disorder

This case means that the value (r) does not change by time and does not response to the control signal $\left(\mathrm{S}_{1}\right)$ which has been received [9]. A Comparison between normal and abnormal bladder radius changes during micturition process is shown in Fig. 8. The equation which describes bladder radius disorder is given as

$$
\mathrm{r}(\mathrm{t})=2 \text { for } 10>=\mathrm{t}>=0
$$



Fig.8: Bladder radius during micturition process . 
In Fig.9, it can be seen that there is no intersection as shown in fig.11 and consequently urethral opening between the two curves because of a little change in the pressure becomes high.

values of $\left(\mathrm{P}_{0}, \mathrm{Q}_{0}\right)$ but this change does not allow lacking out of urine and the beginning of the micturition. Although, we notice the urethral is normal.
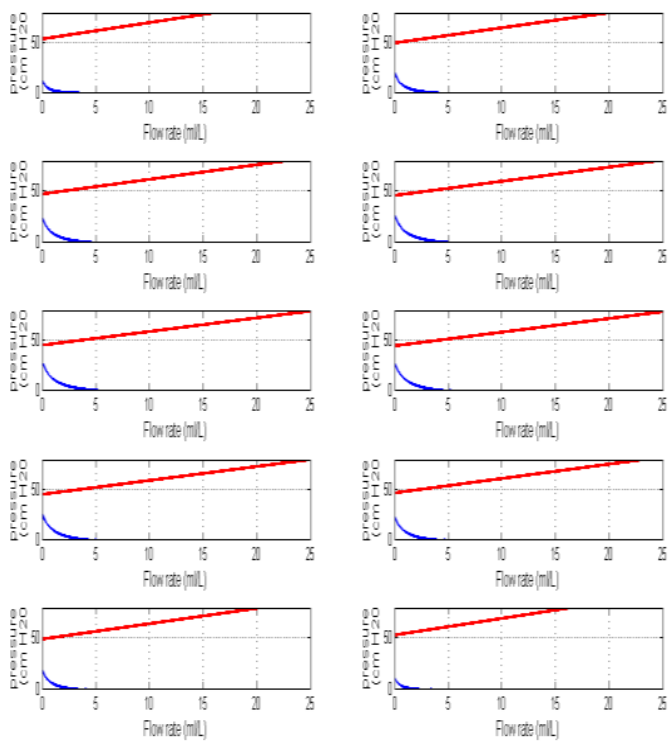

Fig.9:Absence bladder contraction caused by bladder muscles disorder

C. Absence Urethra contraction caused by nervous signals disorder :

- This abnormal case occurs because of the nerve signal $\left(\mathrm{S}_{2}\right)$ which controls the urethral relaxation is sent weak [4] within time (t) as shown in Fig.6. This can be represented mathematically by the same nerve signal disorder Eq.(12) as the following :

$$
\mathrm{S}_{2}(\mathrm{t})=0.5 \text { for } 10>=\mathrm{t}>=0
$$

This abnormal micturition as shown in Fig.10. It can be noticed that there is no intersection between bladder and urethral curve because of non-changing in the value of and $\left(\mathrm{P}_{0 \mathrm{p}}, \mathrm{m}\right)$. Therefore, the curves of $(\mathrm{BOR})$ and (URR) do not equate at any time .
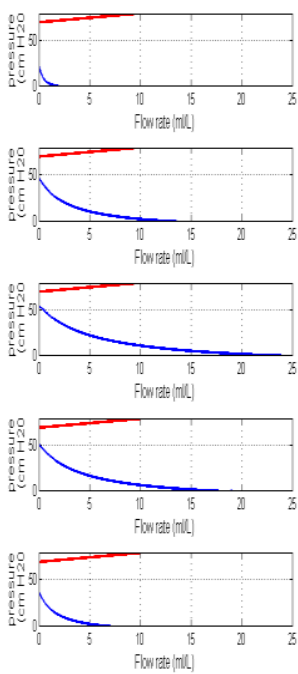
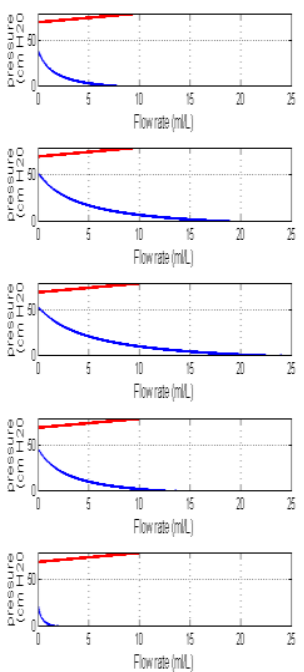

Fig.10: Absence Urethra contraction caused by nervous signals disorder. D.

Obstructed Flow:

This case often occurs due to infravesical obstruction[6]. We represent this abnormality mathematically in Eq.(13) by assuming of high value of $\left(\mathrm{P}_{\mathrm{h}}\right)$ more than normal value
$\mathrm{Ph}_{-} \mathrm{H}(\mathrm{t})=35$ for $10>=\mathrm{t}>=0$

This causes no intersection between the urethral curve and the bladder curve as shown in fig.12. Also, we notice that the bladder works normally.

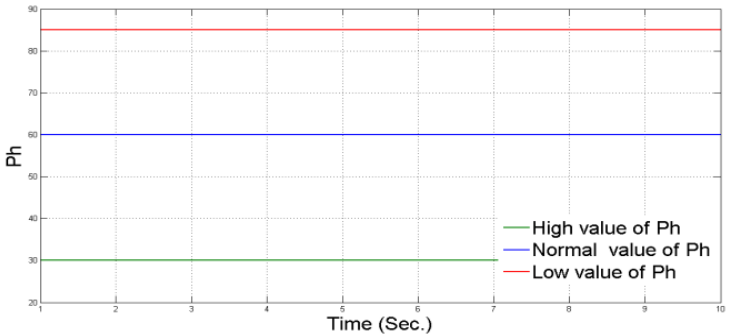

Fig.11: Abnormal values of $(\mathrm{Ph})$ that control urethral.
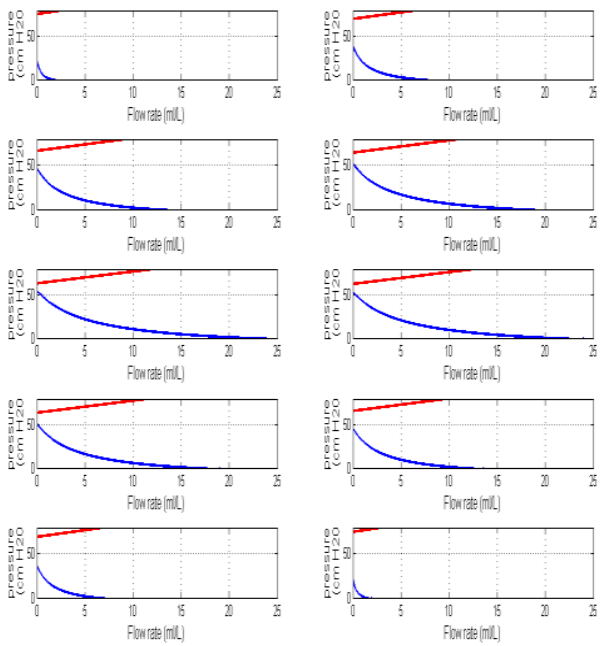

Fig.12: Obstructed Flow, the value of $\left(\mathrm{P}_{\mathrm{h}}\right)$ is high.

$\boldsymbol{E}$.

Irregular Flow:

Here the patient is unable to hold urine during the filling phase (urinary incontinence)[10]. This case is called (Sphincteric Weakness)[11] . It is opposite to the previous case, where the value of $\left(\mathrm{P}_{\mathrm{h}}\right)$ in Eq.(14) is less than normal value (low urethral opening pressure) as shown in fig. 11 .

$$
\mathrm{Ph}_{-} \mathrm{L}(\mathrm{t})=85 \text { for } 10>=\mathrm{t}>=0
$$

The abnormal micturition is shown in fig.13. We notice that the bladder is normal and the intersection exists constantly.
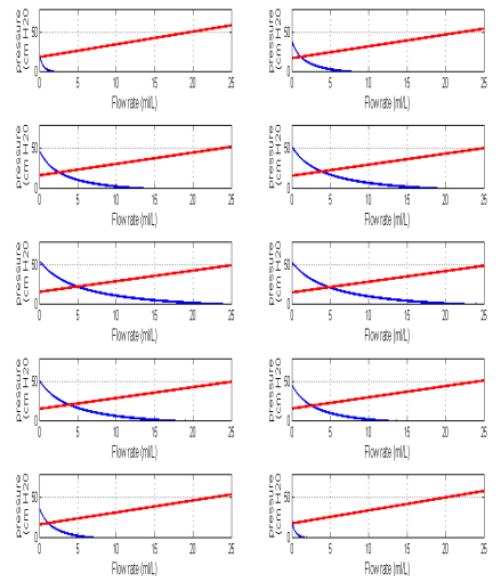

Fig.13: Irregular Flow caused by uncontrolled sphincter contraction, the value of $\mathrm{P}_{h}$ is low. 


\section{F. Intermittent Flow:}

Representing this disease mathematically by occurs of oscillation in the value of $\left(\mathrm{P}_{\mathrm{h}}\right)$ by using equation Called ( $\left.\mathrm{Ph} \_\mathrm{O}\right)$ :

$\mathrm{Ph}_{-} \mathrm{O}(\mathrm{t})=\mathrm{A}(\mathrm{u}(\mathrm{t}-\phi)-\mathrm{u}(\mathrm{t}-\phi-\tau))$ for $0<=\mathrm{t}<\mathrm{t}$

There are four parameters that describe it, (A) $\mathrm{Ph}$

amplitude , $\phi$ initial phase , $(\tau)$ pulse width of the high pulses and $(\mathrm{t})$ pulse rate are shown in Fig.14. The abnormal micturition can be represented in fig.15. We notice that the bladder is normal and the oscillation intersection exists.

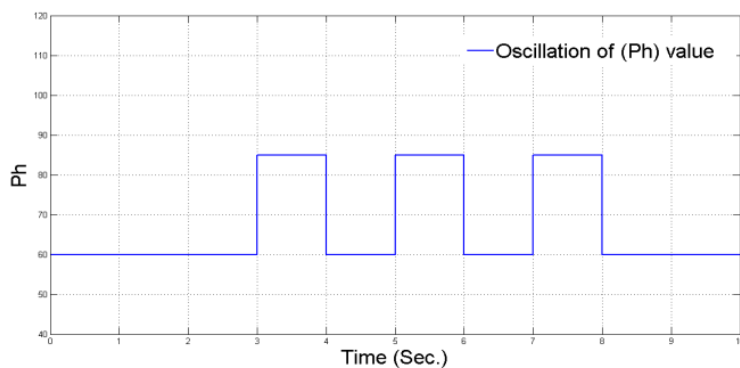

Fig.14: Oscillation values of $(\mathrm{Ph})$
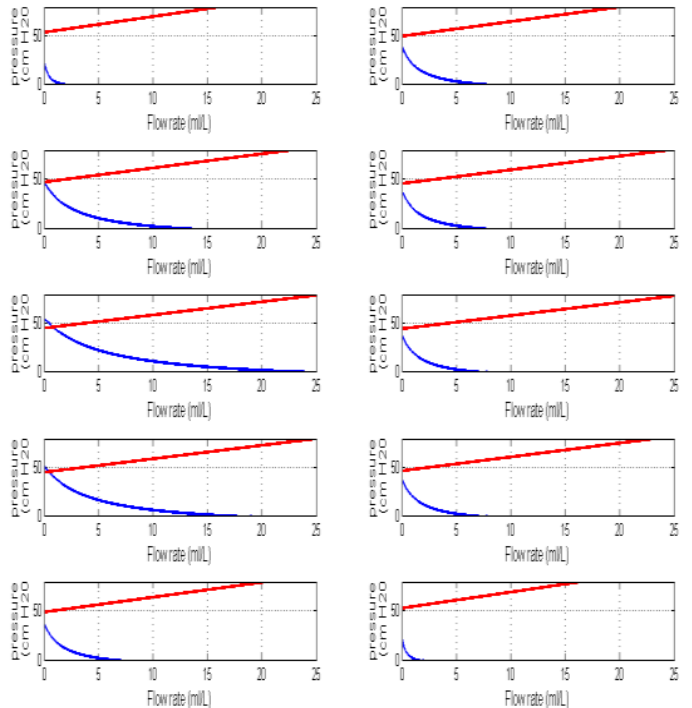

Fig.15: Intermittent Flow caused by oscillation in the value of) $\mathrm{Ph}$ ) by time.

\section{CONCLUSION}

A modified version of the LUTS mathematical model succeeded in representation abnormal micturition process cussed by six types of dysfunctions which are: absence bladder contraction caused by Nervous signals disorder, Absence bladder contraction caused by bladder muscles disorder, absence Urethra contraction caused by nervous signals disorder, Obstructed urine Flow, Irregular urine Flow and Intermittent urine Flow . Simulations were run in Matlab 7 and the results were observed in figures shown relations between bladder and urethra pressure against flow-rate. This study will help us in the future to find an intelligent solutions for controlling the disorders of lower urinary tract system.

\section{REFERENCES}

[1] W. Fletcher, F. T. Smith, and C. Fry, "A Computer Simulation of Micturition," London, 2005.

[2] J. Q. Clemens, "Basic bladder neurophysiology.," Urol. Clin. North Am., vol. 37, no. 4, pp. 487-94, Nov. 2010.

[3] I. B. Celik, A. Varol, C. Bayrak, and J. R. Nanduri, "A one dimensional mathematical model for urodynamics," in 5th joint ASME/ JSME Fluids Engineering Conference, 2007, pp. 1-7.

[4] J. Groen, "Functional modelling of voiding," Erasmus Univeristy Rotterdam, 1996

[5] D. J. Griffiths, "Urodynamic Assessment of Bladder Function," Br. J. Urol., vol. 49, no. 1, pp. 29-36, Feb. 1977.

[6] M. Heldoorn, J. L. Van Leeuwen, and J. Vanderschoot, "Review Modelling the biomechanics and control of sphincters," J. Exp. Biol., vol. 4022, pp. 4013-4022, 2001.

[7] J. Křen, M. Horák, and F. Zá, "MATHEMATICAL MODEL OF THE MALE URINARY TRACT," vol. 145, no. 2, pp. 91-96, 2001.

[8] G. A. Van Koeveringe, B. Vahabi, P. H. D. K. E. Andersson, and P. H. D. R. Kirschner-herrmans, "Detrusor Underactivity: A Plea for New Approaches to a Common Bladder Dysfunction," Neurourol. Urodyn., vol. 728, no. June, pp. 723-728, 2011.

[9] B. Coolsaet and C. Blok, "Detrusor properties related to prostatism," Neurourol. Urodyn., vol. 5, no. 5, pp. 435-447, 1986.

[10] F. Schmidt, P. Shin, T. M. Jorgensen, J. C. Djurhuus, and C. E. Constantinou, "URODYNAMIC PATTERNS OF NORMAL MALE MICTURITION: INFLUENCE OF WATER CONSUMPTION ON URINE PRODUCTION AND DETRUSOR FUNCTION," J. Urol., vol. 168, pp. 1458-1463, 2002.

[11] Y. Ziya, G. Ate, Ö. A. L, A. Karaköse, M. Pekedis, Ö. Karal, and F. Utku, "Does Urinary Bladder Shape Affect Urinary Flow Rate in Men with Lower Urinary Tract Symptoms?," Sci. World J., vol. 2014, pp. 1-6, 2014. 